\title{
Some considerations on evaluating and structuring environmental issues for sustainable energy production
}

\author{
Klaus-Dieter Fröhner \\ System- und Orgplanungen, 23843 Bad Oldesloe, Germany
}

\begin{abstract}
Environmental issues were for a long time questions that could not easily be addressed publicly. Thereafter, environmental issues were frequently turned into topics, very often fostering solid research. Rapid advancement brought global dimensions into focus of the issues. This ended up assuming environmental issues being central elements for industrial design and development. By looking at it in a systematic way, environmental issues were in a first phase characterizing problems, in a second phase marking repair activities, and in a third phase restricting design to overcome the problems on an elaborated level. The attempts to set-up global standards for design ended up a bit illusory, because when it comes up to design a lot of different fields, sciences, and settings are involved, seen from the point of mechanical engineering science having tens of years of practice to set-up design for real world problems. This leads to scrutiny of evaluating and designing environmental issues to improve the set-up and the orientation of projects. From the start it has to be stated that it cannot be overcome that an analytical approach for the handling of environmental issues has to take into consideration that reality is different and complex. By this approach complex processes can be qualified to give them a lay-out not only for understanding. Structuring has to start beginning with the core environmental process. The process orientation in a complex environment has to be supported by rational reasoning and referring. The examination gives a first outline to handle problems related with sustainable energy production in a small country, making evaluation of processes more comparative and reliable.
\end{abstract}

Keywords: Evaluation; structuring; process chain; sub processes; sustainable energy production.

\section{Starting with a general approach}

Transformation and transition of societies and economies have become normal in a globalizing world, transformation being a term to explain the various changes and conversion processes in the former real socialist countries, transition being a more general term to explain the activities of catching up with the developed countries. In the countries of the former real socialist society both processes had to be set up at the same time. For this the former socialist countries had to look for examples in other countries to stimulate their change. This procedure had also been used by the to-day developed countries, when they had the necessity to catch up, still being an approach to-day to adapt to change in areas where others are ahead. A general explanation for these processes was given by the modernization theory. This theory tries to explain the superiority of modern democracies and market economies in comparison to others.

After the former socialist countries had gone through state and institution building, the modernization process seemed to be mapped out after having joined the EU. But the strict following of western models had and has to be questioned because the western model states are partly also facing severe problems after the crisis of 2009 with the slow-down of their economies. To be successful in the actual phase of transition, targets and tasks have to be reconsidered and reestablished in the light of the limited resources of the modernizing states and their social and economic realities. This asks for increased rational reasoning and referring for positioning and developing of national resources and efficient and effective process orientation for development, especially if it comes up to establishing energy production.

This general approach will be exemplified for sustainable energy production, giving an example for Lithuania, in some way typical for a small country.

Corresponding author: Klaus-Dieter Fröhner. E-mail address: k.-d.froehner@web.de

http://dx.doi.org/10.3846/enviro.2014.019

(C) 2014 The Author. Published by VGTU Press. This is an open-access article distributed under the terms of the Creative Commons Attribution License, which permits unrestricted use, distribution, and reproduction in any medium, provided the original author and source are credited. 


\section{Conditions of a small country after transformation period}

Because of the past of the society with an egalitarian setting and because of the experience of setting up a state of its own as a common task of the people there is a very positive attitude of Lithuanian citizen towards state issues [8]. Providing the state with energy can certainly be addressed as a state issue, especially because of the dependence of the Lithuanian infrastructure from Russia because of the past, possibly tangling sovereignty.

The society and its members, because having gone through state- and institution-building because of regained sovereignty, are marked by elements of a loyal society, perhaps in contrast to the more individually oriented societies of western countries. This binding element can still be seen as strong after the phase of transformation [8], making people more inclined when state issues are being addressed.

During hundreds of years of not full sovereignty or even not existing independence the Lithuanian people preserved their identity by inheriting songs, poems and stories of Lithuanian history and heroes in the marvelous setting of the Lithuanian nature. This is the background why sustainability is a widely accepted approach chaired especially among authorities and universities.

The former socialist countries did not establish a vivid industry serving the needs of the people. This resulted for a small country like Lithuania, left mostly with fragments of industrial complexes of the U.S.S.R., having often served as suppliers, in not making it easy to come up with products for the world market. But for catching up, world class products are needed especially when setting up new infrastructure in energy producing areas. To promote world class products innovation is needed. Expenditures concerning research and development are seen as a decisive step for promoting innovation. But in 2007 the funding allocated into R\&D constituted only 0,17\% of the Gross Domestic Product of Lithuania, the majority financed by state funds, whereas the EU goal by 2010 should be $3 \%$ with a high amount from the private sector [9]. The small amount for research resources asks e.g. for an efficient usage of the limited amount to make catching up feasible. Here will be hopefully assumed later on, that the local national industry can serve to some extent as a supplier for elements of equipment for the infrastructure in energy producing areas to establish a competitive edge on a regional market.

\section{Remarks on alternative energy production}

Countries not having any natural resources of oil, natural gas, or coal are inclined to substitute their imports and have a triple advantage out of installing alternative energy because of carbon credits, less cash for imports, and less dependence on vulnerable supply chains. In Western Europe, especially Finland and Sweden have successfully implemented biomass energy, $20 \%$ respectively $16 \%$ account for the energy supply in both countries. But the conditions for energy production out of biomass in these countries with a high percentage of areas covered with forest may contribute to this high amount, being more complicated to achieve by other countries because of their different set of restrictions. Therefore, all options of alternative energy production with biomass, consisting out of different materials as wood, straw, manure, bio-rubbish etc. that can be burnt, used for producing pallets, bio-ethanol, biogas etc. have to be considered to increase energy supply by alternative resources. With alternative energy accounting year by year to a higher percentage to power generating in Western Europe, the processes of alternative energy production (biomass, wind and solar) have to be looked at especially concerning their contribution to general advantages seen being combined with this form of energy production.

The general advantages seen going along with different processes for producing alternative energy out of biomass had been surveyed by a study based on the Intergovernmental Panel on Climate Change's special report on renewable energy sources and climate change mitigation [3]. To calculate the outcomes of energy production turned out being complicated. The eco balance sheets for different processes with different materials showed different consequences for the environment, living conditions, and economy. The usage of bio-waste from other processes with little transportation efforts showed best results. But these kinds of processes of energy production cannot often be achieved, showing that sustainability is more complex than expected. The study showed on a general level that regenerative energy production is not per se a sustainable energy production source.

With sustainability for the core processes burning, production of ethanol etc. differing considerably due to the input used for the processes, the potential of sustainability has to be cared for. But the core processes of energy production are furthermore accompanied by a large amount of manmade processes, e.g. transportation, influencing sustainability to a great extent. All processes of the process chain have to be cared for, when alternative energy production should turn out as sustainable energy production.

There may be arguments that the precise depiction of energy producing processes may be a little bit too exaggerated. But by paleoclimatologic analysis of ice cores from Antarctic and Arctic it could be found that people were already pumping greenhouse gases into the atmosphere 5000 years before the Industrial Revolution, air bubbles in the ice cores suggest. There is the belief that in the early days of global warming, humans must have been, by the installation of wetlands for rice production, the major force for the rise in the southern hemisphere [5].

All this asks for emphasis to avoid greenhouse gases by systematic approaches. 


\section{Systemizing sustainable energy production processes}

For systemizing and evaluating sustainable energy production processes the extension of examination on the whole process chain has to be considered. In focus should be an approach that could help to give some explanations concerning the complexity of sustainability in combination with real-life-processes. This means that it is very important to look also at the sub processes that surround the core process of energy production in the process chain. This should lead to help finding out effective and efficient set-ups of processes.

In metal industry it is very well known that production processes differ due to different inputs, obstacles and restrictions instituting varying outputs. This has also been exemplified in contrasting processes in European and Japanese industry by using structured processes. The direct function of production, the core process, was seen like a process chain surrounded by anticipating and succeeding indirect functions as well as by surveying and escorting indirect functions [7].

For sustainable energy production this structuring and systemizing approach will also be applied, the core process of energy production (burning biomass, gasing biomass, generating electricity by wind etc.) seen being surrounded by participatory sub processes and follow-up sub processes. Furthermore, the core processes and the sub processes have to be managed by surveying processes and the stability of the core process has to be maintained by escorting sub processes (Fig. 1).
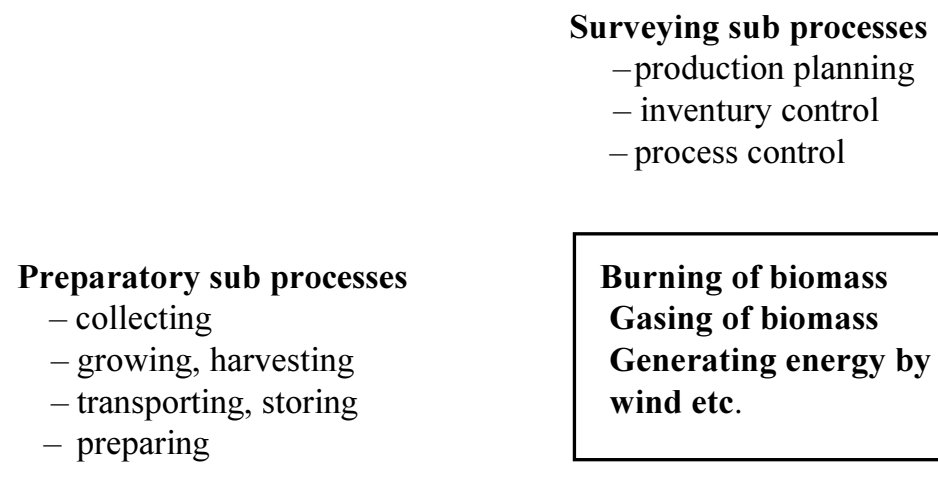

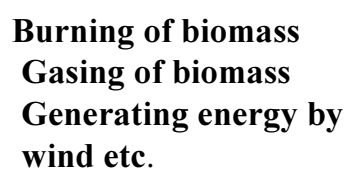
Escorting sub processes
- service
- maintenance

\author{
Follow-up sub process \\ - storing \\ - transporting \\ - distributing
}

Fig. 1. Core process of energy production with surrounding sub processes

The preparatory sub processes can have a large variety, like collecting of biomass or growing and harvesting of biomass. The material has to be transported, and it has to be prepared for the process, e.g. by chopping and drying. Storing can be a complicated sub process when very voluminous straw has to be stored, protecting the straw e.g. from humidity. The followup sub processes differ also due to the core process. Storage is easy when gas or liquid is being produced. But in these cases distribution may need a lot of transportation due to the location of the energy production site. But transportation may also not be easy for electricity being generated, because of distribution and storage problems. For the managing of the core and the sub processes the production and the pre products have to be planned, also using inventory control. The stability of the core process has to be guaranteed by escorting sub processes. Service and supplying of spare parts for maintenance enable and support the core process of energy production. It is obvious that the number of the sub processes depends on the kind of the core process and the way and where the core process has been set-up. The set and the layout of the manmade sub processes distinguish to a high extent how efficient and how effective a core process can be served and finally if the attribute sustainable energy production can be used for the whole process chain.

\section{Sustainable energy production for a small country after transformation period}

Out of the subjects discussed so far, it is obvious that the set of restrictions and binding elements, that have to be considered when preparing installations going along with topics of vital interest, cannot be generalized and differ from society to society. This approach is also valid for looking at the installations themselves, because a generalizing approach concerning core processes of alternative energy production cannot be assumed. However, it can be assumed that the diversity of alternative energy processes is very high, making it necessary to depict the processes and the combined sub processes.

It is also obvious, that a small country may not tend to use all technological options being possible to produce alternative energy. For being efficient a critical number of systems have to be installed in a country, especially when the language is a barrier having to be overcome and ambitious maintenance has to be realized. This may be looked at with a first glance that installing alternative energy production is more complex or less efficient in a small country. Therefore, depicting alternative energy production processes in a differentiated way is necessary. 
Because wood as a natural resource had already been used by tradition in Lithuania to some extent for decentralized heating, chopped wood is being used in the last years to an increasing extent in centralized, already realized energy systems, substituting imported gas. This resource only having limited not used potential today, other alternative energy resources have to be considered. Wind energy, being transformed to energy in a few wind farms in Lithuania will be here under scrutiny, because a nucleus has been laid in Lithuania for this energy source. Scrutiny will be realized in two steps. The first step will be depicting the core process and the surrounding sub processes as shown in chapter 4 . The second step will be a depiction of the options of possible reality because of usage of different equipment for energy production.

\section{Surveying sub process \\ - process control \\ Generating energy by wind \\ Escorting sub processes \\ - service \\ - maintenance}

\author{
Follow-up sub process \\ - distributing
}

Fig. 2. Generating energy by wind with the surrounding sub processes for a limited number of wind turbines connected with the national grid

Wind turbines on wind towers convert a fraction of the atmosphere's kinetic energy into electricity. Because there is plenty of wind in certain areas, especially high up above the ground, preparatory sub processes are not necessary for this kind of energy (Fig. 2). Furthermore, the follow-up processes account to low costs with a small number of installed wind turbines, making the integration into the national grid feasible. Therefore, the only surveying sub process will be process control. The only cost and labor intensive sub processes for this set of restrictions will be the escorting sub processes of service and maintenance, accounting to high costs when the number of wind turbines is too small to install a national company to realize the tasks. But wind turbines also emit noise asking for a special set-up of the wind towers concerning neighboring living areas [1].Therefore, generating electricity by wind, being referred to as an energy source of near-zeroemission [6], earning carbon credits, can only be assumed as near-zero-emission for a limited set of conditions. When it comes up to a larger number of wind turbines, production planning for energy is becoming an intensive task, in cooperation with the national grid, and distribution and storage can amount to increasing emissions and high costs, installing supplements for the national grid and implementing storage facilities, the latter ones eventually asking for high investments.

The analysis of the production process so far shows that even producing electricity by wind turbines may not turn out as a near-zero-emission process. By looking at the investment itself the situation becomes more complicated, because the investment on towered wind turbines is very high, having to be imported because of lack of technology competence, constituting high imported carbon emissions. The transportation of the heavy blades, turbines, and tower segments, having to be realized by heavy duty trucks, being limited by the infrastructure, can also constitute high emissions. The public will ask for explanations for the frequently set-up of this capital intensive and labor extensive investment not being in accordance with the loyal society of Lithuania, with a very high unemployment rate for young people, disturbing the binding element being necessary for issues of national interest. This can be partly compensated when technological options of producing of equipment in the country will be considered, as already stated in chapter 2 . This can be seen for the production and setting up of wind towers.

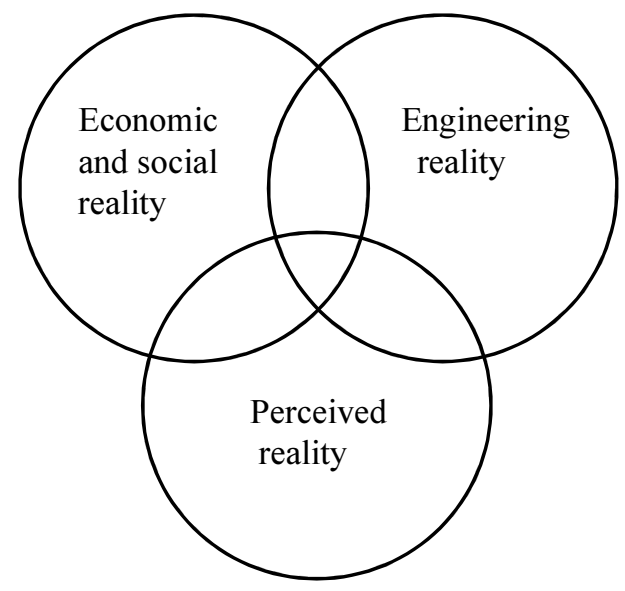

Fig. 3. Examination of environmental projects [8] 
The normal way of setting up would be the import of steel segments being assembled to post-tensioned towers on foundations produced in Lithuania. But if post-tensioned hybrid towers out of concrete and steel [2] or cross laminated timber connector elements for wooden towers [4] would be installed, the labor balance could have been changed because of production of the segments out of concrete or out of wood in Lithuania. This would support regional or national construction industry, asking for less explanation. But these approaches will also ask for research funding of these processes being new respectively very new even in the developed countries, possibly opening up markets in Eastern Europe, if companies succeed to implement the production processes for wind tower segments made out of concrete or cross laminated wood.

Looking at the depicted wind technology by the adjustment of national targets and tasks it can be constituted that the engineering reality of this technology seems to support sustainability to a large extent. But the technology also asks for high financial resources in a state with limited financial assets and there is only little impact by installing wind technology on the employment situation. Looking at figure 3, having been stated as desirable examination of environmental projects in the transition area of Lithuania, there is a third dimension to be cared for shaping of projects, the perceived reality. The perceived reality can be seen ambivalent too for this technology, because the technology seems to support the running of not vulnerable energy production on one hand side but on the other side does not support the improvement of the economic and social situation in an adequate way. Finally, the emitted noise may be perceived as noise pollution, when there are only few positive benefits for the society going along with wind turbine installations, because noise perception being influenced to a high extent by psychological explanations. This means that this technology cannot generally allocated in the area covered from all three realities addressed in figure 3. By this approach satisfying engineering reality, economic and social reality, and perceived reality cannot be achieved, mostly due to the national situation of Lithuania. Wind energy power can rather be seen closing a gap than serving within the next years with a large number of wind farms as an important energy source.

The analysis so far lays open that the appliance of alternative energy producing processes is limited if the whole process chain and a wide set of indicators and phenomenal explanations are being used.

\section{The change of environmental challenges}

Looking at the remarks made so far, it can be stated that there had been and there are tremendous changes in environmental challenges, going to be summarized by four statements: The first statement characterizing the long term change of environmental orientation in environmental engineering, the second statement characterizing the setting where the processes is going to be set-up, this statement having been derived from the concrete situation of the Lithuanian society, state, and economy as an example of a small society as depicted in chapter 2 . The third statement is being derived from the change of attitude of looking at the process in a holistic way, characterized by the moment taking down the criteria seen being accomplished. The forth statement is having been evolved from reasoning about the obstacle, to serve a differentiated view on the process of energy production as depicted in chapter 4 . Thus the four statements can be presented:

- From the improvement of established processes to design of new processes

- From processes in ideal settings to processes in real settings in complex societies

- From ex-ante positive assumptions to ex-post reasoning and referring

- From isolated punctual reasoning of the obstacle to an orientation on the whole process chain

By looking at it by a supervisory approach it can be stated that the core processes of energy production are based on natural processes, whereas the sub processes have a high influence of manmade layout whilst supporting the core process. Therefore, sustainable energy production is dependent on many variables and manmade processes having to be adjusted for effective and efficient energy production in a normally very special setting, as given as example for the small country Lithuania. It is obvious that not all obstacles can be considered, very often because of lack of data, but considering a holistic approach brings projects of energy production closer to sustainable production, incorporating low greenhouse gas emissions, low costs, and high benefits for society.

\section{Conclusions}

Alternative energy producing processes can be made more comparative and reliable concerning sustainability when the processes are going to be structured. The attitude of looking at the processes has to be changed from isolated punctual reasoning to an orientation on the whole process chain. All sub processes have to be incorporated when depicting a core process of energy production. For a high degree of sustainability not only the core process and the adjacent sub processes but also the way these processes are being embedded in a complex society have to be looked at. Like this true and reliable results can be gained.

\section{References}

[1] Butkus, D.; Grubliauskas, R.; Mazuolis, J. 2012. Research of equivalent and maximum value of noise generated by wind power plants, Journal of Environmental Engineering and Landscape Management 20(1): 27-34. http://dx.doi.org/10.3846/16486897.2011.633337

[2] Bögl, S.; Gläser, C.; Hierl, M., Traute, M. 2013. Vorgespannte Hybridtürme für Windenergieanlagen (Post-Tensioned Hybrid Towers for wind energy plants), Bauingenieur 88(7/8): 301-306. 
[3] Creutzig, F.; Popp, A.; Plevin, R.; Luderer, G.; Minx, J.; Edenhofer, O. 2012. Reconciling top-down and bottom-up modelling of future bioenergy deployment, Nature Climate Change 2(5): 320-327. http://dx.doi.org/10.1038/nclimate1416

[4] Kraler, A.; Kögl, J.; Maderebner, R.; Timmers, R. 2013. Systemverbinder für Holzflächenelemente (SHERPA- Cross Laminated Timber-Connector), Bauingenieur 88(9): 385-391.

[5] Mitchel, L.; Brook, E.; Lee, J. E.; Buizert, Ch.; Sowers, T. 2013: Constraints on the late Holocene anthropogenic contribution to the atmospheric methane budget, Science 342(22 november 2013): 964-966. http://dx.doi.org/10.1126/science.1238920

[6] Marvel, K.; Kravitz, B.; Caldeira, K. 2013. Geophysical limits to global wind power, Nature Climate Change 3(2): 118-121. http://dx.doi.org/10.1038/nclimate1683

[7] Fröhner, K.-D. 1991. Some designing principles of production systems based on field research in Europe and Japan, in Grubbström, R. W., Hinterhuber H.H.(eds): Productionn Economics: Issues and Challenges for the 90 `s, Amsterdam-London-New-York-Tokio,1991: Elsevier, 99-103.

[8] Fröhner, K.-D. 2011. From transformation to transition as a permanent process, some aspects of environmental issues being important for a small country after transition period, in Proc. of the $8^{\text {th }}$ International Conference Environmental Engineering, Vilnius, Lithuania, 2011 : Technika, $94-99$.

[9] Petrauskaite, N. 2010. Key priorities for high technologies development in Lithuania in Ginevicius, R. (ed) Proc of the $6^{\text {th }}$ International Conference Business and Management, Vilnius, Lithuania, 2010:Technika, 461-468. 